\title{
The cardiac atlas project: rationale, design and preliminary results
}

\author{
Pau Medrano-Gracia ${ }^{1 *}$, Michael Backhaus ${ }^{1}$, David A Bluemke², Jae Do Chung ${ }^{1}$, Brett R Cowan ${ }^{1}$, Paul J Finn ${ }^{3}$, \\ Carissa G Fonseca ${ }^{3}$, Peter J Hunter ${ }^{1}$, Alan H Kadish', Daniel C Lee ${ }^{4}$, Joao AC Lima², Kalyanam Shivkumar ${ }^{5}$, \\ Wenchao $\mathrm{TaO}^{3}$, Alistair A Young ${ }^{1}$
}

From 2011 SCMR/Euro CMR Joint Scientific Sessions

Nice, France. 3-6 February 2011

\section{Objective}

To develop a statistical map of regional wall motion in healthy and diseased populations using a standardized database of cardiovascular magnetic resonance studies.

\section{Background}

The Cardiac Atlas Project (CAP) is a NIH sponsored international collaboration to establish a web-accessible structural and functional atlas of the normal and pathological heart as a shared resource for the clinical, research and educational communities.

\section{Methods}

Images, derived ventricular contours, and clinical text data have been contributed from several studies. To date, 2864 cases have been contributed from the MESA study [1] comprising asymptomatic volunteers, and 470 cases have been contributed from the DETERMINE
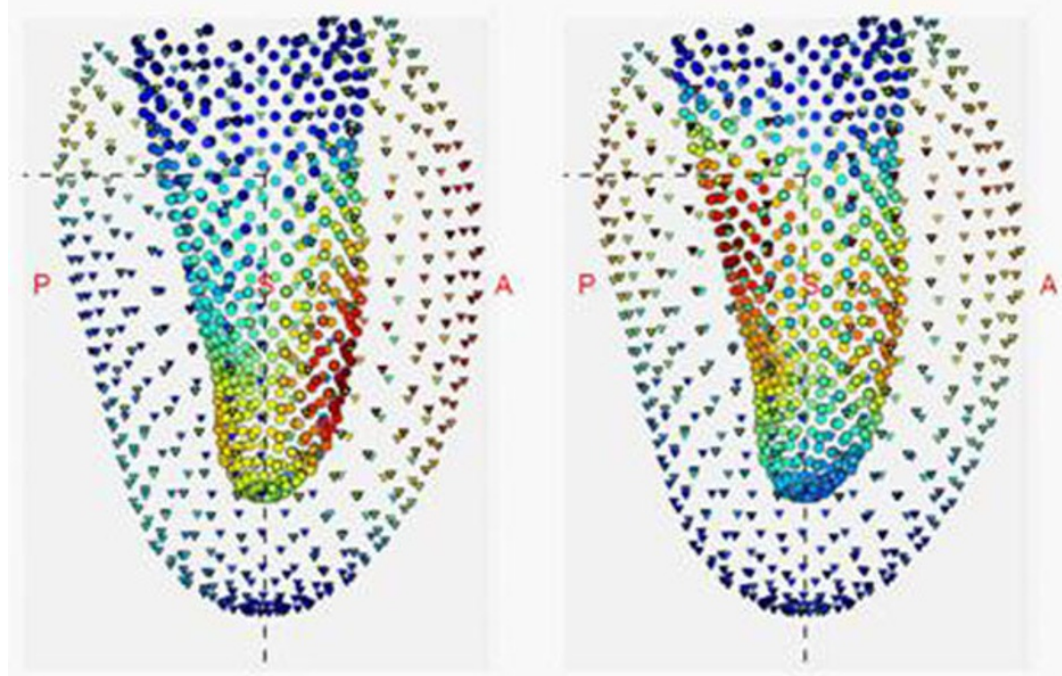

Figure 1 Regions of statistical difference between MESA (asymptomatic) and DETERMINE (myocardial infarction) subgroups. Left: antero-septal infarct DETERMINE subgroup. Right: infero-posterior infarct DETERMINE subgroup. Colours indicate Hotelling $\mathrm{T}^{2} \mathrm{p}$-values, blue least significant, red most significant. Viewpoint is from the septum with the posterior wall to the left. Triangles show epicardial points, and circles show endocardial points, sampled from the average MESA geometry at end systole.

The University of Auckland, Auckland, New Zealand

Full list of author information is available at the end of the article

(c) 2011 Medrano-Gracia et al; licensee BioMed Central Ltd. This is an open access article distributed under the terms of the Creative Commons Attribution License (http://creativecommons.org/licenses/by/2.0), which permits unrestricted use, distribution, and reproduction in any medium, provided the original work is properly cited. 
study [2] comprising patients with myocardial infarction. DICOM images were de-identified using HIPAA compliant software [3]. Only those cases with informed consent and IRB approval compatible with data sharing were included. To illustrate the potential of this resource, a preliminary statistical analysis was performed on a subset of 300 cases from DETERMINE and 200 cases from MESA. A finite element model of the left ventricle was customized to each case using a standardized mapping which registered each anatomical location within a standard coordinate system. Shape and motion distributions were quantified across cohorts using principal component analysis and multidimensional statistical tests.

\section{Results}

The analysis automatically determined the major characteristics and statistical distribution of shape and motion in the MESA and DETERMINE groups. The main modes were associated with well-known clinical indices of cardiac remodelling including size, sphericity and mitral valve geometry. The Hotelling $\mathrm{T}^{2}$ test showed significant differences between the MESA cohort and subgroups of the DETERMINE cohort, stratified according to infarct location (Figure 1).

\section{Conclusion}

Standardized mapping of shape and motion facilitates statistical characterization of cardiac performance, providing a powerful resource for the scientific community. Applications for use of the resource can be made from the website (http://www.cardiacatlas.org).

\footnotetext{
Author details

${ }^{1}$ The University of Auckland, Auckland, New Zealand. ${ }^{2}$ Department of Radiology, Johns Hopkins Hospital, Baltimore, MD, USA. ${ }^{3}$ Diagnostic CardioVascular Imaging, UCLA, Los Angeles, CA, USA. ${ }^{4}$ Bluhm Cardiovascular Institute, Northwestern Memorial Institute, Chicago, IL, USA. ${ }^{5}$ UCLA Cardiac Arrhythmia Center, Los Angeles, CA, USA.
}

Published: 2 February 2011

\section{References}

1. Bild, et al: Am J Epidemiol 2002, 156:871-881.

2. Kadish, et al: J Cardiovasc Electrophysiol 2009, 20:982-987.

3. U.S. Department of Health and Human Services:, Privacy Rule, 45 CFR Parts 160, 162, and 164 .

doi:10.1186/1532-429X-13-S1-072

Cite this article as: Medrano-Gracia et al:: The cardiac atlas project: rationale, design and preliminary results. Journal of Cardiovascular Magnetic Resonance 2011 13(Suppl 1):O72
Submit your next manuscript to BioMed Central and take full advantage of:

- Convenient online submission

- Thorough peer review

- No space constraints or color figure charges

- Immediate publication on acceptance

- Inclusion in PubMed, CAS, Scopus and Google Scholar

- Research which is freely available for redistribution

Submit your manuscript at www.biomedcentral.com/submit 